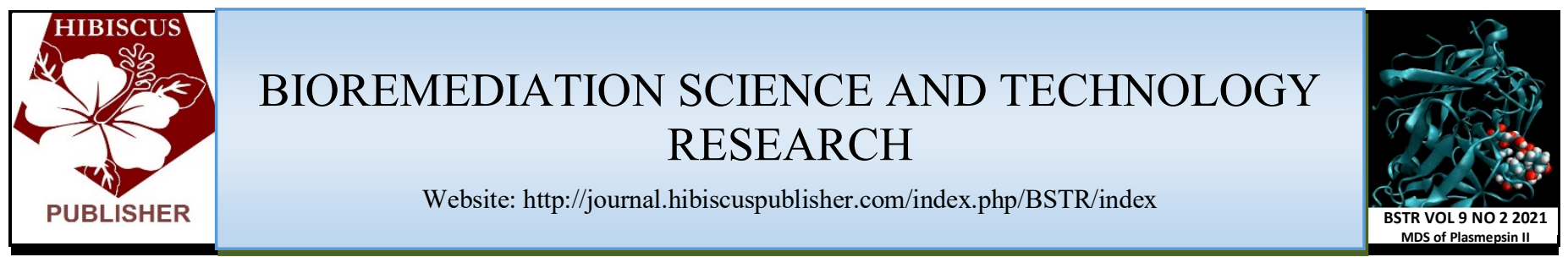

\title{
Effect of Cowpea Seed Beetle (Callosobruchus maculatus) Infestation on Selected Landraces of Bambara Groundnut During Storage
}

\author{
Isma'ila Muhammad $^{1 *}$, Nasiru Abdullahi ${ }^{2}$, Abdulmalik Bala Shu'aibu ${ }^{3}$ Ibrahim Musa $^{4}$ Bawa Zakari Gambo ${ }^{5}$ \\ Zainab Abubakar Adamu ${ }^{1}$
}

\begin{abstract}
${ }^{1}$ Department of Botany, Faculty of Science, Gombe State University, PMB 127, Gombe, Nigeria.
${ }^{2}$ Department of Biological Sciences, Faculty of Science, Gombe State, University PMB 127, Gombe, Nigeria.

${ }^{3}$ Department of Zoology, Faculty of Science, Gombe State University, PMB 127, Gombe, Nigeria.

${ }^{4}$ Department of Agronomy, Faculty of Agriculture, Federal University of Kashere, PMB 0182, Gombe, Nigeria.

${ }^{5}$ Department of Plant Science, Faculty of Science Modibbo Adama University, Yola, Nigeria.
\end{abstract}

\author{
*Corresponding author: \\ Dr.Isma'ila Muhammad, \\ Department of Botany, \\ Faculty of Science, \\ Gombe State University, \\ PMB 127, \\ Gombe, \\ Nigeria. \\ Email: ismuha@gsu.edu.ng
}

\section{HISTORY \\ Received: 23 ${ }^{\text {rd }}$ Oct 2021 \\ Received in revised form: $15^{\text {th }}$ Nov 2021 Accepted: 24 ${ }^{\text {th }}$ Dec 2021}

\section{KEYWORDS}

Callosobruchus maculatus

Bambara groundnut

Landraces

Oviposition

Infestation

\begin{abstract}
The study was carried out to assess the effect of Callosobruchus maculatus infestation on selected Bambara groundnut (Vigna subterranean) landraces in Gombe during storage to determine the Landrace (s) that are less susceptible to infestation caused by $C$. maculatus during storage. The trial was done in the Botany laboratory of Gombe State University, Gombe. Seeds were collected from five different Landraces, 40 grams each of healthy and C. maculatus infestation free seeds were infested with two males and three females. Completely Randomized Design (CRD) with three replicates was used to assess the effects of $C$. maculatus infestation on the selected landraces of Bambara groundnut during storage. The results of the analysis of variance displayed significant differences $(p \leq 0.05)$ among the parameters studied. It indicated that the Mottled and Cream landraces are relatively less susceptible and witness lower damage from the bruchids attack 14.6 $(36 \%)$ and $17(46 \%)$, whereas Red and Black landraces are more susceptible $24(61 \%)$ and 22 (57\%) (recorded higher damage from the C. maculatus in terms of percentage weight loss recorded). These results showed the existence of variation among the different Bambara groundnut landraces used due to the infestation of $C$. maculatus. It can be observed from this study that the use of infestation free landraces at storage time may perhaps be a worthwhile and auspicious factor for integrated pest management especially on bruchids in Bambara groundnuts. additionally, Mottle and Cream landraces might be employed as sources of resistance genes for the subsequent plant improvement program.
\end{abstract}

\section{INTRODUCTION}

Bambara groundnut (Vigna subterranean L. Thouars) is an African indigenous legume crop that has been grown for centuries. Bambara groundnut is among the most commonly used grain in Nigeria, and help provide $14-24 \%$ of the protein requirements of most of the population [1]. The high contents of lysine and protein of this crop make it a natural supplement to essential diets for fruits, tubers, cereals, roots [2]. The entire plant is known for soil improvement because of nitrogen fixation [3]. Bambara groundnut can play a significant role as a source of protein. Seeds of this crop can make a complete food because it contains enough amounts of proteins, fats and carbohydrates. Averagely, Bambara groundnut seed is known to contain 17-24\% protein, 54.5-69.3\% carbohydrate and 5.3-7.8 fat [4]. Its seeds can be used as an important source of food and nutritional security due to their high nutritional contents and is an excellent source of iron. calcium, and fibre. Calcium is significant in aiding blood clotting. Based on records, red seeds of this crop are advantageous in regions where there is iron deficiency [4]. Bambara groundnut fatty acid composition of the oil is appropriate for edible purposes. It also contains thiamine, riboflavin, vitamins, carotene, and niacin but is very low in ascorbic acid content [5]. Brink et al., also mentioned that the dried leaves used for fodder can contain $16.7 \%$ crude protein, $31.9 \%$ crude fibre, $6.8 \%$ ash, and $1.7 \%$ fat. Bambara groundnut genotypes exhibit a wide range of genetic variations some of which include cream, brown, maroon and black with differences 
in the seed sizes, seed eyes and thickness of seed coats with some identified Bambara groundnut varieties comprising of; brown, red, black, white-eyed cream coloured, black-eyed cream coloured, cream coloured, strip-brown, and flecked/speckled/spotted, among others [6].

Bambara groundnut is not attacked by pests and disease in any of its regions of production. Nevertheless, in most situations, it can be susceptible to several fungal diseases [1]. It has a low insect and pest susceptibility [7]. Bambara groundnut is vulnerable to infestation by bruchids which are fields to store pests. The level of infestation in storage is influenced by the type of storage structures employed and the variety of seeds used. The temperature of storage also influences infestation in local stores. Bambara groundnut and Cowpea are majorly infested by two species of Bruchidae; Callosobruchus maculatus and Callosobruchus subinnotatus, however, Callosobruchus maculates is particularly the most common species that attacked many legumes [8]. Callosobruchus maculatus is a species of beetle generally recognized as cowpea weevil. C. maculates is an agricultural pest of Africa and Asia which is currently range all over the tropical and subtropical region of the world. The larvae of $C$. maculatus feed and develop exclusively on the legume seeds (Fabaceae) hence the name bean beetle. The adult does not need food nor water and can spend their limited lifecycle of approximately 1 to 2 weeks mating and laying eggs on the seeds [9].

In spite of the significant rank of this crop in Gombe state and Nigeria as a whole, the supply of its seeds for consumption and planting is always restricted by bruchids (Callosobruchus maculatus) attack. Such attacks occur majorly during storage time. In view of the above, this research was conducted to determine the best landraces which are less susceptible to the attack of Callosobruchus maculatus on selected Landraces of Bambara groundnut during storage and to determine which among the Landraces can exhibit minimal weight loss during storage.

\section{MATERIALS AND METHODS}

\section{Experimental site}

The experiment was led in the Botany Laboratory of the Biological Sciences Department, Gombe State University, Gombe Nigeria. Located at latitude $10^{\circ} 15^{\prime} \mathrm{N}$ and longitude is $11^{0} 10^{\prime} \mathrm{E}$. The altitude varied, from $466 \mathrm{~m}$ to $767 \mathrm{~m}$. The mean temperature range of the study area is between $22^{\circ} \mathrm{C}$ to $33^{\circ} \mathrm{C}$, whereas the relative humidity is around $72 \%$.

\section{Procurement and Sample Preparation}

Clean (uninfected) seeds of selected Bambara groundnut Landraces used in this study were obtained from Gombe main Market, Kwami, Bojude of Kwamil L.G.A Gombe State, the northeastern part of Nigeria, and the seed were refrigerated for 24 hours in order to disinfect the seeds for possible egg laid. Infested seeds were also procured which served as a stock culture.

\section{Stock Culture}

The culture of Callosobruchus maculatus used in this study was sourced from the infested Bambara groundnut seeds. It was then kept and reared under relative humanity and temperature in the Laboratory (at Room temperature). It was then sieved to obtained newly emerged Collosobruchus maculatus that were used for the experiment.

\section{Experimental Design}

The experiment was laid down in a Complete Randomized Design (CRD) and replicated three times, comprising five selected landraces of Bambara groundnut Figure 1, Black (Burobu), Read (Mai Bargo), Striped Black (Bidi), mottled (Giwa) and Cream (Benteli) respectively. $40 \mathrm{~g}$ of each of the landraces were placed in to $10 \mathrm{~cm}$ kiln jar, they were subsequently infected with two males and three females Collosobruchus maculatus (2:3) and covered with fine mesh to prevent the insects from escaping throughout the study period.

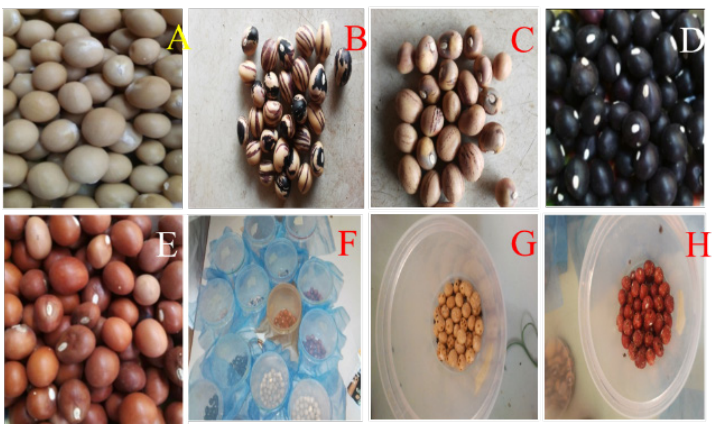

Fig. 1. A to E constitutes the types of Bambara groundnut landraces used $\mathrm{F}$ is the composition of different landraces infested with male and female Collosobruchus maculatus while $\mathrm{G}$ and $\mathrm{H}$ represent some of the damages caused by Collosobruchus maculatus.

\section{Data Collection and Analysis}

Each kiln jar was observed after every three days interval taking the records of eggs laid (Oviposition) for 9 days and the number of adults emerged after every four days interval starting from 36 days after infestation (DAI), 40 DAI, 44 DAI, and 48 DAI respectively. At the end of the experiment, the landraces of Bambara groundnut used in this study were assessed to determine the weight loss recorded during an infestation. Data collected were subjected to analysis of variance (ANOVA) using (SPSS 16.0). The results are expressed as Mean values (standard deviation), the difference between the treatments mean were evaluated using the least significant difference (LSD).

\section{RESULTS AND DISCUSSION}

The results of the analysis of variance showed significant $(p \leq 0.005)$ variation among all the traits studied and the landraces used in this study, the results indicated that oviposition observed from this study improved with the increase in time afterwards of infestation of Bambara groundnut landraces with bruchids (Table 1). It was equally observed during the sampling period that, fewer egg counts were recorded from the Mottled (Giwa) landrace as compared to the other landraces used. Similarly, the number of eggs laid on the various landraces differed significantly $(p \leq 0.005)$ among the several seed coat colours. It was also observed that Ovipositions on Red, black, and striped black landraces were not significantly $(\mathrm{p} \leq 0.005)$ higher than those recorded on mottled and, Cream landraces, which appears to be significantly different $(\mathrm{p} \leq 0.005)$ with fewer ovipositions observed.

Table 1. Effect of C. maculatus on selected landraces of Bambara groundnut on Number of eggs Laid (oviposition count).

\begin{tabular}{llll}
\hline & \multicolumn{3}{l}{ Number of eggs laid (Oviposition count) } \\
\hline Landraces & 3DAI & 6 DAI & 9DAI \\
\hline Black (Burobu) & $26.0 \pm 4.6^{\mathrm{a}}$ & $25.0 \pm 4.0^{\mathrm{ab}}$ & $29.0 \pm 2.5^{\mathrm{a}}$ \\
Mottled (Giwa) & $9.3 \pm 1.5^{\mathrm{c}}$ & $14.7 \pm 1.5^{\mathrm{c}}$ & $18.3 \pm 2.1^{\mathrm{b}}$ \\
Red (Mai Bargo) & $28.0 \pm 6.6^{\mathrm{a}}$ & $30.0 \pm 3.6^{\mathrm{a}}$ & $31.0 \pm 2.5^{\mathrm{a}}$ \\
Striped Black (Bidi) & $25.3 \pm 2.5^{\mathrm{a}}$ & $21.7 \pm 2.0^{\mathrm{b}}$ & $26.0 \pm 3.6^{\mathrm{a}}$ \\
Cream (Benteli) & $17.3 \pm 1.5^{\mathrm{b}}$ & $21.0 \pm 4.4^{\mathrm{b}}$ & $15.7 \pm 4.0^{\mathrm{b}}$ \\
Note: DAI Days After Infestation & &
\end{tabular}

- 32 - 
Similarly, the results on the effect of Collosobruchus maculatus infestation on the Bambara groundnut landraces based on the emergence of adult count showed significant variation $(p \leq 0.005)$, similarly, there was highly significant variation among the landraces used and between the weeks observed during this study. The result indicated that mottled landrace exhibited the lowest mean value recorded (Table 2). The trend of the results obtained based on the response of the landraces to infestation by Collosobruchus maculatus showed Red, Black and Striped Black to be the landraces with the highest mean number of adult emergence count after infestation with Collosobruchus maculatus.

Table 2. Response of C. maculatus on selected landraces of Bambara groundnut based on adult count Emergence.

\begin{tabular}{lllll}
\hline \multicolumn{5}{c}{ Adult emergence count } \\
\hline Landraces & 36DAI & 40DAI & 44DAI & $48 \mathrm{DAI}$ \\
Black (burobu) & $21.0 \pm 3.0^{\mathrm{a}}$ & $20.3 \pm 4.0^{\mathrm{ab}}$ & $22.7 \pm 4.7^{\mathrm{a}}$ & $20.3 \pm 2.5^{\mathrm{a}}$ \\
Mottled (Giwa) & $7.3 \pm 2.0^{\mathrm{b}}$ & $11.7 \pm 0.7^{\mathrm{c}}$ & $12.0 \pm 3.0^{\mathrm{b}}$ & $13.7 \pm 2.1^{\mathrm{b}}$ \\
Red (Mai bargo) & $22.7 \pm 5.5^{\mathrm{a}}$ & $26.3 \pm 4.7^{\mathrm{a}}$ & $24.7 \pm 3.5^{\mathrm{a}}$ & $21.3 \pm 2.5^{\mathrm{a}}$ \\
Striped Black (Bidi) & $19.7 \pm 1.5^{\mathrm{a}}$ & $17.7 \pm 1.5 \mathrm{bc}$ & $19.3 \pm 1.5^{\mathrm{a}}$ & $15.3 \pm 6.7^{\mathrm{a}}$ \\
Cream (Benteli) & $12.0 \pm 1.0^{\mathrm{b}}$ & $15.7 \pm 4.0^{\mathrm{bc}}$ & $11.3 \pm .3 .5^{\mathrm{b}}$ & $13.0 \pm 3.8^{\mathrm{b}}$ \\
Note: DAI Days After Infestation & & &
\end{tabular}

The result on the percentage weight loss recorded significant variation $(p \leq 0.005)$ among the different Bambara groundnut landraces used. A similar trend was observed on the percentage of damage to landraces by Collosobruchus maculatus on Bambara groundnut as it was observed on the number of adult emergence and ovipositions (Table 3). The most susceptible landrace to Collosobruchus maculatus observed in this study was, Red (Mai bargo) which recorded $61.7 \%$, whereas the most tolerant landrace to the infestation by Collosobruchus maculatus was Mottled (Giwa) 36.6\% indicating that this variety can be used in many breeding studies to develop varieties resistant to Collosobruchus maculatus infestation.

Table 3. Percentage response of $C$. maculatus infestation on selected landraces of Bambara groundnut based on weight loss (damage) observed.

\begin{tabular}{lll}
\hline \multicolumn{3}{l}{ Percentage weight loss (damage) } \\
\hline Landraces & WTL & PWTL \\
Black (burobu) & $22.8 \pm 5.3^{\mathrm{ab}}$ & $57.0 \pm 13.2$ \\
Mottled (Giwa) & $14.6 \pm 2.9^{\mathrm{c}}$ & $36.6 \pm 7.4$ \\
Red (Mai bargo) & $24.7 \pm 1.0^{\mathrm{a}}$ & $61.7 \pm 2.6$ \\
Striped Black (Bidi) & $18.9 \pm 1.2^{\mathrm{bc}}$ & $47.2 \pm 3.1$ \\
Cream (Benteli) & $17.4 \pm 2.1^{\mathrm{bc}}$ & $46.5 \pm 5.3$ \\
Note: WTL Weight Loss PWTL Percentage Weight Loss &
\end{tabular}

The results from this study evidently displayed that oviposition and adult emergence count of Collosobruchus maculatus glaringly affected the selected landraces used. The highest counts were obtained from Red (Mai Bargo) landrace throughout the sampling days, whereas the least counts were observed from the Mottled (Giwa) landrace. This result suggests that Mottled landrace possibly had a better genetic structure to either lessen oviposition or hatchability of the laid eggs. This result concurs with a finding which stated that the emergence of adults and oviposition of Collosobruchus maculatus observed from their studies revealed that landraces can vary based on their response to Collosobruchus maculatus [10].

Correspondingly, it was also observed that variation in landraces colours used in this study has greatly affected the oviposition of bruchids during this study. It was observed that Cream coat landraces scored lower oviposition and emergence counts during this study. This indicates that Cream coat landraces possess higher tolerance to the infestation by Callosobruchus maculatus while other landraces evaluated based on colours indicated susceptibility to Collosobruchus maculatus. This result is in agreement with the report by [11]. It similarly, be inferred from these results that, C. maculatus chooses darker backgrounds to lay their eggs as compared to the brighter or milky-coloured backgrounds used in this study. Based on this outcome it can be established that C. maculatus uses this technique as a strategy for the survival of the young or newly hatched; similarly, darker surfaces despite being a better radiator of heat than brighter surfaces, are also considered as a better absorber of heat [12]. Thus, eggs laid on those dark backgrounds might have healthier incubation conditions concerning warmth needed for better hatchability of the eggs.

This condition of the darker surfaces can also elucidate the higher adult emergence recorded between these Red, and blackcoated landraces used in this study. The reaction of $C$. maculatus to prefer the seed-coat colour of Bambara groundnut in this study is supported with the reports by many researchers like [13][14] they maintained that, insects have a preference for colours. Nevertheless, records especially on the effects of seed damage on oviposition and survival of $C$. maculatus are somewhat inconsistent. For example, [15] in their experimentations on twenty-two cowpea varieties (five less susceptible, four moderately susceptible, and thirteen most susceptible) with and without seed coat, and on ten Bambara groundnut varieties respectively stated that seed coat had no importance in protecting cowpea and Bambara groundnut seeds from attack by $C$. maculatus. They suggested that the growth and development of C. maculatus in cowpea and Bambara groundnut depends on the nutritional contents of the seeds. The choice for Red, Black and Striped Black landraces to other landraces by the bruchids therefore, suggests that those landraces used in this study could have varied in their nutritional compositions.

\section{CONCLUSION}

The experiment was led to determine the effect of $C$. maculatus infestation on selected landraces of Bambara groundnut during storage. The results showed that Red, Black, and Striped Black are more susceptible, while Mottled and Cream landraces are less susceptible to Collosobruchus maculatus attack. The study concludes that despite other characteristics of seeds such as size, nutritional value and chemical composition are recognized to affect their resistance to insect attacks, however, attributes like variability among landraces and coat colour can still contribute to the susceptibility of grains to storage pests. It was also concluded from this study that $C$. maculatus have the potentials to attack all the Bambara groundnut landraces, nonetheless, some landraces such as Mottled and Cream landraces are less susceptible than the other landraces (Red, Black, and Striped Black) used in this study. These findings will serve as an advisory report for Bambara groundnut farmers, industry and marketers knowing that Mottled and Cream Landraces are vulnerable than the other landraces used.

\section{REFERENCES}

1. Muhammad B, Muhammad I. Detection Of Cucumber Mosaic Virus (Cmv) From Bambara (Vigna Subterranean (L) Verdc.) Abuja J Agric Environ AJAE. 2021;1(1):253-8.

2. Azman Halimi R, Barkla BJ, Mayes S, King GJ. The potential of the underutilized pulse bambara groundnut (Vigna subterranea (L.) Verdc.) for nutritional food security. J Food Compos Anal. 2019;77:47-59.

3. Sidibé A, Meldrum G, Coulibaly H, Padulosi S, Traore I, Diawara $\mathrm{G}$, et al. Revitalizing cultivation and strengthening the seed systems of fonio and Bambara groundnut in Mali through a community 
biodiversity management approach. Plant Genet Resour Characterisation Util. 2020;1-18.

4. Muhammad I, Rafii MY, Ramlee SI, Nazli MH, Harun AR, Oladosu Y, et al. Exploration of Bambara Groundnut ( Vigna subterranea ( L .) Verdc, an Underutilized Crop , To Aid Global Food Security: Varietal Improvement, Genetic Diversity and Processing. Agronomy. 2020;10(766):1-21.

5. Abba HM, Umar BA, Mohammed I. Leaf epidermal anatomy of selected varieties of Bambara groundnut in Gombe State, Nigeria. Int J Curr Res Biosci Plant Biol. 2019;6(09):44-52.

6. Khan MMH, Rafii MY, Ramlee SI, Jusoh M, Al Mamun M. Genetic analysis and selection of Bambara groundnut (Vigna subterranea [L.] Verdc.) landraces for high yield revealed by qualitative and quantitative traits. Sci Rep. 2021 Apr 7;11(1):7597.

7. Effa EB and, Uko AE. Food security potentials of Bambara groundnut ( Vigna subterranea ( L .) Verdc .). Int J Dev Sustain. 2017;6(12):1919-30.

8. Karidiatou, Gnankambary.,, Teyoure, Benoit., Joseph, Batieno., Nerbewende, Sawadogo., Mahamadou, Sawadogo., Jean, Baptiste, Tignegre., Djibril, Yonli., Tinga, Jeremy Ouedraogo. Genetic Variability Induced by Gamma Radiation in Cowpea [( Vigna unguiculata L . ( Walp )] in Burkina Faso. Eur Sci J. 2019;15(15).

9. Ndong A, Kébé K, Thiaw C, Diome T, Sembéne M. Genetic Distribution of the Cowpea (Vigna Unguiculata (L.) Walp) Bruchid (Callosobruchus maculatus F., Coleoptera, Bruchidae) Populations in Different Agro-Ecological Areas of West Africa. J Anim Sci Adv. 2012;2(7):616-30.

10. Seram D, Senthil N, Pandiyan M, Kennedy JS. Resistance determination of a South Indian bruchid strain against rice bean landraces of Manipur (India). J Stored Prod Res. 2016 Oct 1;69:199-206.

11. Muhammad Mamoon-ur-Rashid, Rahatullah, Khalid Abdullah, Muhammad Naeem AAA and SH. Entomocidal Studies Of Some Plant Materials Against Pulse Beetle, Callosobruchus Chinensis ( Bruchidae : Coleoptera ) On Stored Chickpea ( Cicer Arietinum ) Entomocidal Studies Of Some Plant Materials Against Pulse Beetle ,. Pak Entomol. 2018;40(2):71-5.

12. Mofunanya AAJ, Namgbe EE. Assessment of Damage Due to Callosobruchus maculatus ( Coleoptera : Bruchidae ) Infestation on Germination and Nutrient Quality of Vigna Unguiculata L . ( Walp ). J Agric Vet Sci. 2016;9(12):96-101.

13. Magagula, C.N. and Maina YT. Activity of Callosobruchus maculatus ( F .) ( Coleoptera: Bruchidae ) on selected bambara groundnut ( Vigna subterranea L . Verdc .) landraces and breeding lines. J Nat Sci Res. 2012;2(3):67-75.

14. Habiba K, Nukenine EN. Screening of Bambara groundnut ( Vigna subterranea ) lines for Callosobruchus maculatus resistance in the Far North Region of Cameroon. J Renew Agric. 2014;2(1):18-22.

15. Kosini D, Saidou C, Nukenine EN. Physico-chemical Properties and Resistance of Ten Bambara Groundnut ( Vigna subterranea ) Varieties to Attack by Callosobruchus maculatus ( Fabricius ) ( Coleoptera : Chrysomelidae ) in the Sudano-sahelian and Sudanoguinean Zones of Cameroon. J Exp Agric Int. 2017;15(1):1-14. 